\title{
Endotracheal repair of an iatrogenic tracheal laceration in a COVID-19 patient scheduled for surgical tracheostomy: a case report
}

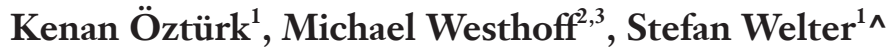 \\ ${ }^{1}$ Department of Thoracic Surgery, Lung Clinic Hemer, Hemer, Germany; ${ }^{2}$ Department Pneumology, Lung Clinic Hemer, Hemer, Germany; \\ ${ }^{3}$ University of Witten/Herdecke, Witten, Germany \\ Correspondence to: Stefan Welter, MD. Department of Thoracic Surgery, Lung Clinic Hemer, 58675 Hemer, Germany. Email: stefan.welter@lkhemer.de.
}

Background: To the best of our knowledge, this is the first report of a tracheal membrane laceration (TML) repair in a frail COVID-19 patient requiring long term ventilation.

Case Description: We report the rare case of a TML in a COVID-19 patient with respiratory failure scheduled for surgical tracheostomy after three weeks of invasive mechanical ventilation. After exposure of the trachea, the cannula insertion was performed promptly during apnea. Based on ventilation disturbances the diagnosis of a $5 \mathrm{~cm}$ TML was established with flexible bronchoscopy. During the next 24 h every reposition of the patient lead to, the development of mediastinal emphysema and a left-sided pneumothorax, necessitating chest drain placement. Surgical TML repair was inevitable on the next day as the gap could not be bypassed with the tube and repeated dislocations of the tube tip occurred with massive surgical emphysema and ventilator alarms. Using personal protection measures, including FFP-3 masks and face shields for all staff working directly on the patient, we successfully performed endotracheal repair with a running suture through a $14 \mathrm{~mm}$ tracheoscope under jet ventilation. The patient was deemed too frail for open operative repair. The postoperative follow-up was uneventful. There were no further problems with the tracheostomy or the mechanical ventilation. The patient could be weaned from the respirator and finally been discharged for rehabilitation. All staff remained free from virus disease.

Conclusions: Prevention of SARS-CoV-2 aerosol spillage is one of the most challenging parts of COVID-19 patient treatment. Therefore some concerns existed, but we conclude, that endotracheal repair might be a good option to treat frail COVID-19 patients sustaining iatrogenic TML, with acceptable risk for health care personnel.

Keywords: COVID-19; tracheal membrane laceration (TML); endotracheal repair; tracheostomy; case report

Received: 30 May 2021; Accepted: 23 November 2021; Published online: 12 December 2021.

doi: $10.21037 /$ ccts-21-27

View this article at: https://dx.doi.org/10.21037/ccts-21-27

\section{Introduction}

During the current SARS-CoV2 pandemic the treatment of patients with respiratory failure is a particular challenge. The severity of respiratory failure is influenced by the infection, the immune response, existing comorbidities, the respiratory reserve and ventilatory reaction and finally the course of disease progression (1). Those patients requiring long-term mechanical ventilation have the most unfavorable constellation of these factors.

Nosocomial virus transmission is the most feared complication affecting health care providers when treating infected patients. Intubation is known to be associated with a 13-fold relative risk of RNA virus transmission (2) and therefore increased risk of SARS-CoV2 transmission

\footnotetext{
$\wedge$ ORCID: 0000-0002-4194-8215.
} 
(3). Thus tracheostomy and its timing in severely ill COVID-19 patients have to be weighed in the context of the risk of viral transmission as well as the benefits and risks for the patient. Iatrogenic tracheal membrane laceration (TML) is a rare but severe complication of tracheostomy tube insertion (4). The management of large TML, especially if it has a deleterious impact on the provision of mechanical ventilation, has to be outweighed between the deteriorating situation of a frail patient and the infectious risk for the treating staff. We report on the management of a TML in a severely ill COVID-19 patient applying an endotracheal running suture to successfully overcome all associated problems. To the best of our knowledge, this is the first report of a TML repair in a frail COVID-19 patient requiring long-term ventilation. We present the following case in accordance with the CARE reporting checklist (available at https://ccts.amegroups.com/article/ view/10.21037/ccts-21-27/rc).

\section{Case presentation}

A 69-year-old female patient with respiratory failure and bilateral COVID-19 pneumonia was admitted to our intensive care unit in December 2020. She complained about dyspnea and persistent cough for the past 3 weeks. Her oxygen saturation on room air was decreased $\left(\mathrm{SaO}_{2} 85 \%\right)$. Her comorbidities included hypertension, diabetic neuropathy, diabetic nephropathy and a history of breast cancer. Two family members had tested positive for the SARS-CoV2 virus and a third had died of COVID-19 at the age of 95 .

All procedures performed in this study were in accordance with the ethical standards of the institutional and national research committees and with the Helsinki Declaration (as revised in 2013). Written informed consent was obtained from the patient for publication of this case report and accompanying images. A copy of the written consent is available for review by the editorial office of this journal.

She was prescribed oxygen therapy $(4 \mathrm{~L} / \mathrm{min})$ and an empirical course of antibiotics for a bacterial respiratory superinfection (ampicillin and clarithromycin). Despite this, the patient deteriorated, necessitating non-invasive ventilation and, ultimately, after a further 5 days, endotracheal intubation. The bilateral infiltrates progressed (Figure $1 \mathrm{~A}$ ) and ventilation parameters had to be adapted to a worsening $\mathrm{PaO}_{2} /$ inspired oxygen fraction $\left(\mathrm{FiO}_{2}\right)$-index and progressive hypercapnia. The antibiotic regimens were escalated twice (meropenem, piperacillin/tazobactam supplemented with levofloxacin) and voriconazole was added to treat Candida albicans. The SARS-CoV2 PCR was still positive 3 weeks after treatment initiation and meanwhile cytomegalovirus (CMV) immunoglobulins (IgM and $\mathrm{IgG}$ ) were elevated indicating additional CMV pneumonitis (Figure 1B,1C). Ganciclovir treatment for three weeks was therefore commenced and i.v. prednisolone $100 \mathrm{mg}$ per day was administered. As weaning from the ventilator was not possible the decision for surgical tracheostomy was made after interdisciplinary discussion. At that time the respirator was set at assisted biphasic positive airway pressure (BiPAPass), with $\mathrm{FiO}_{2} 50 \%$, positive end expiratory pressure (PEEP) $10 \mathrm{mbar}$ and maximum inspiratory pressure (Pins) of 31 mbar.

Surgical tracheostomy was performed on day 21 in the intensive care unit using personal protective equipment (FFP3 face mask and face shields). While the preparation of the trachea, the $\mathrm{U}$-shaped incision and the elevation and fixation of one tracheal ring were uneventful, the insertion of a rigid tracheostomy cannula (Tracoe ${ }^{\circledR}$, twist plus $8 \mathrm{~mm}$, Tracoe, Germany) proved to be difficult and required 2 attempts due to the short neck and unfavorable angulation. Strict apnoe was kept beginning when the trachea was opened and the oral tube was withdrawn until blocking of the tracheostomy cannula. Restarting mechanical ventilation, the tidal volume could not be increased over $200 \mathrm{~mL}$. At that time tracheal wall injury was suspected. Using the oral endotracheal tube still in place a flexible bronchoscopy was performed, revealing a TML with bleeding edges. The rigid tracheostomy cannula was substituted for a long flexible cannula (TracheoFlex, long $8.0 \mathrm{~mm}$, Rüsch, Germany) with the intention to bridge the lesion. The position was monitored under bronchoscopic vision. During the next $24 \mathrm{~h}$ every reposition of the patient lead to ventilation disturbances, the development of mediastinal emphysema and a left-sided pneumothorax, necessitating chest drain placement (Figure 2A). A second bronchoscopy revealed a larger left lateral full thickness TML, $5 \mathrm{~mm}$ up to the carina with direct view on the esophagus. Additionally, an older lesion above the entrance of the tracheostomy cannula was visible, which possibly was caused by the initial oral intubation (Figure 2B) and this had to be considered as an explanation for how the tip of the tracheal cannula could easily dislocate into the mediastinum causing repeated ventilation disturbances and mediastinal emphysema. Using the flexible bronchoscope, a rough examination of the esophagus did not show any lesion. On day 22 after intubation, we decided to resolve the situation 

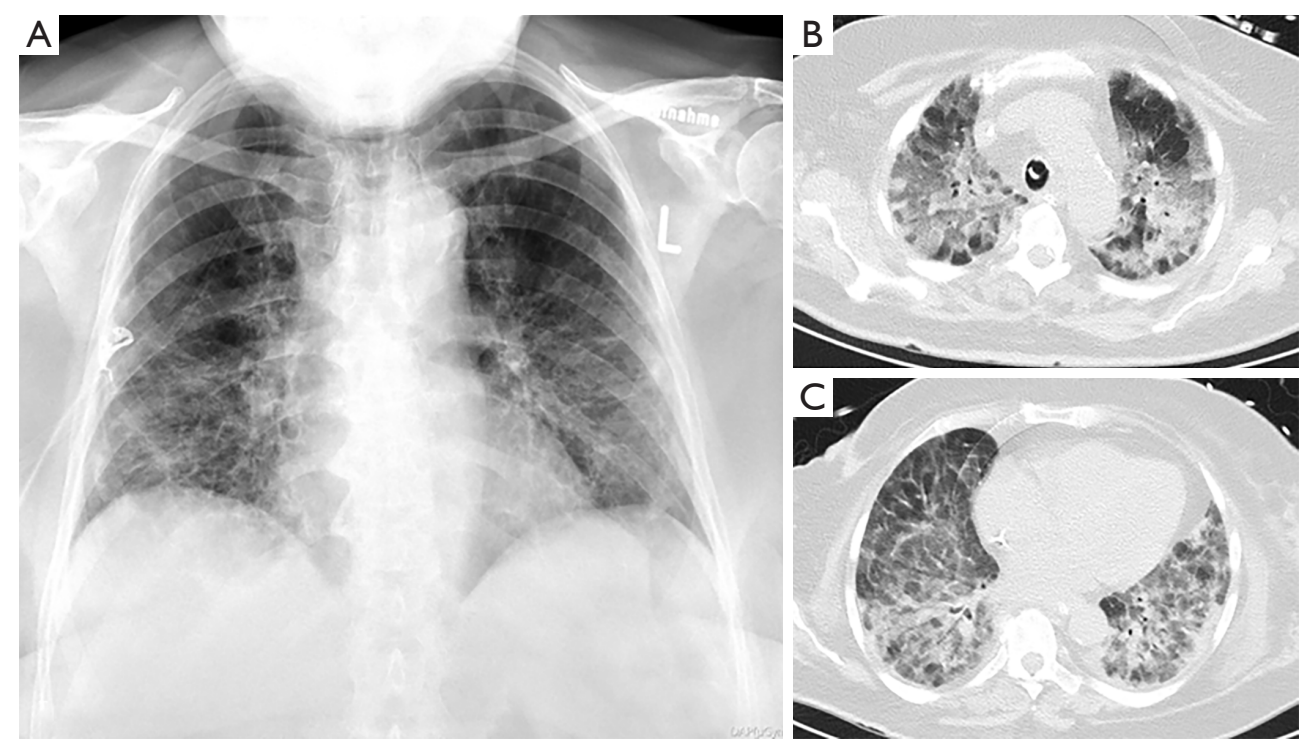

Figure 1 Bilateral infiltrates from COVID-19 and CMV pneumonitis. (A) The chest X-ray on the day of intubation demonstrates bilateral patchy infiltrates in the lower parts of the lung. (B,C) The CT scans on day 18 after intubation show the atypical pneumonic infiltrates from COVID-19 in both lungs with signs of fibrotic changes. CMV, cytomegalovirus.
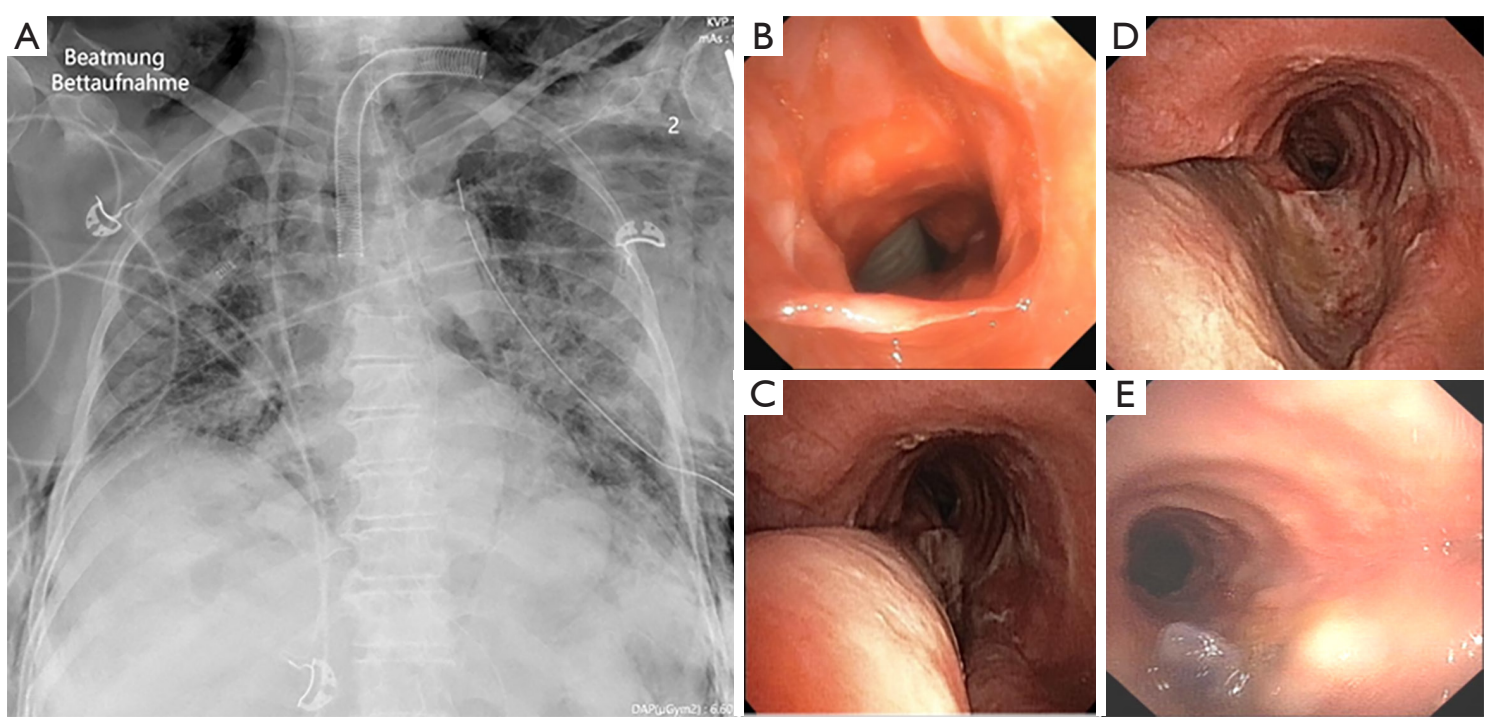

Figure 2 Large TML. (A) Chest X-ray one day after tracheostomy with chest tube insertion on the left side, bilateral pneumonic infiltrates, mediastinal und subcutaneous emphysema and a widening of the tracheal lumen where the tube cuff was located. (B-E) Flexible bronchoscopy views: (B) with at least a superficial mucosa lesion above the entrance of the tracheostomy cannula, (C,D) a huge gap of the posterior tracheal membrane with direct view on the fibrin-covered esophagus and (E) fully closed posterior membrane on the day after operative repair with a visible PDS clip on the left side holding the end of the thread and covered with some mucous and fibrin. TML, tracheal membrane laceration.

with an endotracheal repair as described earlier (5). The interdisciplinary decision was made, taking into account that using a double lumen tube could bridge the lesion, but would prolong the time to weaning the patient from mechanical ventilation and may cause further morbidity.

Endotracheal repair using jet ventilation was performed. 

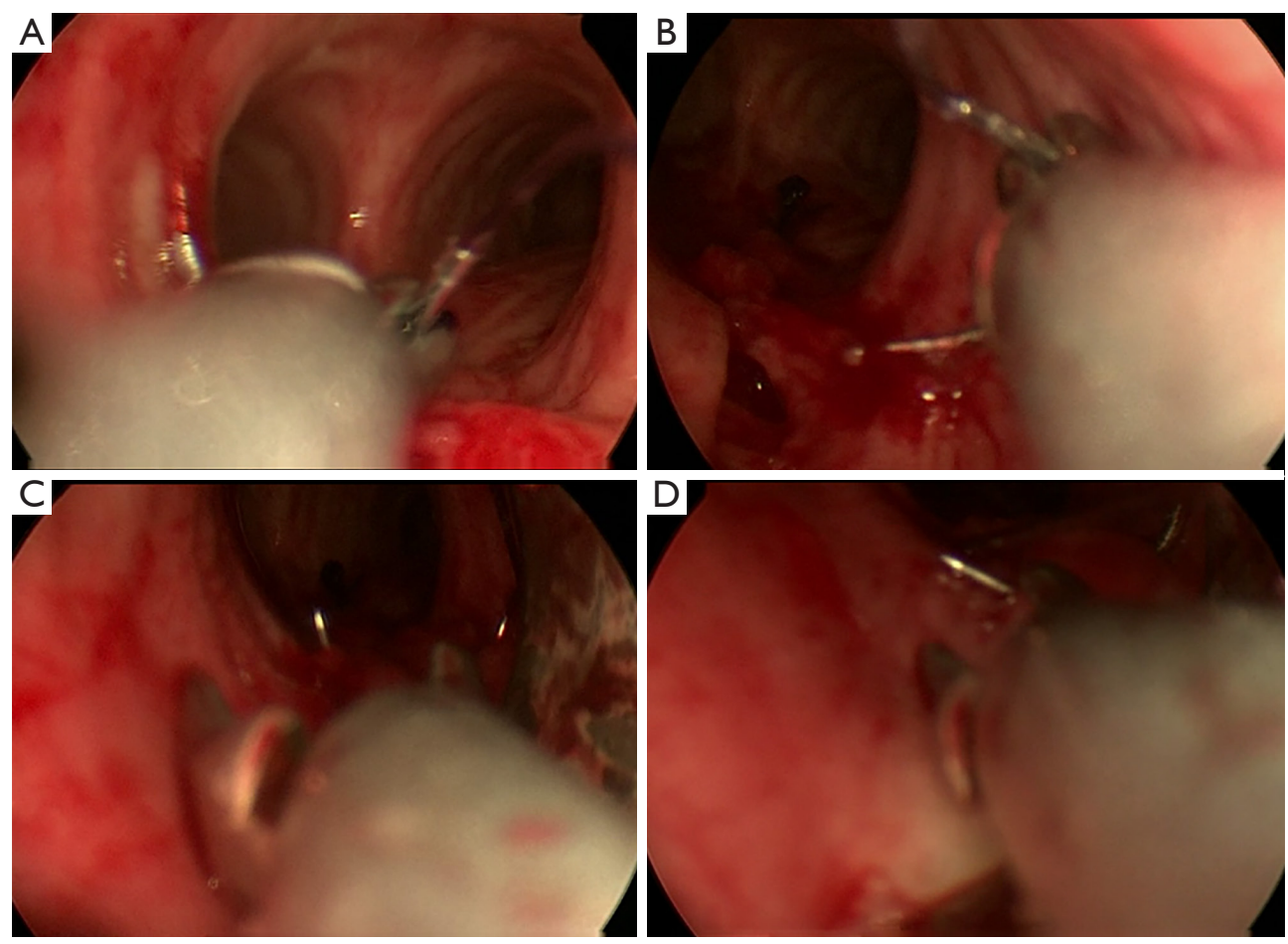

Figure 3 Endoluminal repair through a $14 \mathrm{~mm}$ tracheoscope with a running suture. Schematic representation of an endoluminal TML repair from a different case. The operation video of the COVID-19 patient due to technical difficulties unfortunately could not be recovered. (A) Introduction of the optical needle holder with the UCLX needle through a 14 mm tracheoscope into the tracheal lumen. (B) Rotation of the needle holder to lead the needle tip on the right edge of the ruptured posterior membrane. (C) The needle went through both edges in this case with a small TML. (D) The needle holder is going to grasp the needle tip and extract the needle. TML, tracheal membrane laceration.

The evaluation with a $14 \mathrm{~mm}$ rigid tracheoscope demonstrated a $5 \mathrm{~cm}$ full thickness TML without laceration of the eosophagus but with broad communication with the mediastinum. As security measures non-essential personnel left the room, and the most experienced providers performed the procedure. The large membranous gap could be closed up to the opening of the tracheostomy with a $2 / 0$ Vicryl (UCLX-needle; Ethicon, Norderstedt, Germany) running suture using the optical needle holder (Karl Storz Endoscopes, Tuttlingen, Germany) (5) (Figure 2C,2D). The patient tolerated the jet ventilation with additional oxygen flow $(8 \mathrm{~L} / \mathrm{min})$ through the tracheoscope without relevant respiratory deterioration, except of a transient $(2 \mathrm{~h})$ periinterventional hypercapnia $\left(\mathrm{pCO}_{2}\right.$ of $\left.85 \mathrm{mmHg}\right)$. Subsequently the respiratory situation stabilized, and no further air way problems occurred (Figure 2E). Weaning from mechanical ventilation began on day 31 . The tracheal cannula could be removed on day 25 after tracheostomy. On day 59 after intubation the patient was partially mobilized. Then she was transferred to a rehabilitation unit, still suffering from a critical illness polyneuropathy not fully resolved, hoarseness and residual restrictive pulmonary disease. Six weeks later in a telephone phone call, the patient reported that she had recovered after rehabilitation, could be discharged home and was fully independent in her activities of daily life.

\section{Discussion}

\section{Etiology of TML}

Mainly difficult intubation and dilative tracheotomies were reported as being associated with iatrogenic TML in Germany, whereas surgical tracheostomy was uncommon (6). TML during surgical tracheostomy is rare and only described in case reports $(4,7)$. In our case we suspect a TML during initial intubation leaving a weak area in the posterior membrane, visible as an older lesion above the entrance of the tracheostomy (Figure 2B). The rigid tracheostomy cannula contained a pointed applicator that 
might have perforated and loaded the already weakened posterior tissue, causing further damage to the posterior membrane during attempts to advance the device forward. Furthermore, we believe that the added pressure on the team to minimize aerosol exposure, the patient requiring prompt actions and the restrictions from the extensive protective clothing including face shields added to the complexity of the procedure. In general, advanced age, female sex, prednisolone medication and inflammation due to tracheobronchitis might have weakened the membranous portion of the trachea as described by others (8). In this case, poorly controlled diabetes with multiple complications and the presence of an older TML were additional risk factors at the time of tracheostomy. In summary, age, female sex, prednisolone treatment, complicated diabetes and local inflammation as general risk factors in combination with a local weak area from earlier TML and the use of a rigid cannula in unfavorable anatomical circumstances contributed to this deleterious complication (Appendix 1). As a consequence we would discuss delaying tracheostomy until the patient is virus negative and always call for experienced airway surgeons even for a simple tracheostomy.

\section{Protective measures}

Endoluminal repair was assessed to be the least aggressive and best suitable intervention for this frail patient, albeit with maximum aerosol exposure from jet ventilation. The surgeon had overcome the COVID-19 infection and relied on his immunity whereas all other staff members kept distance as far as possible. Furthermore, the windows were opened for rapid change of the room air. Personal protective equipment included FFP-3 masks, double gloves, coated coveralls, protective goggles and face shields for the surgeon, anesthetist and scrub nurse, as recommended by current guidelines $(9,10)$. Portable high-efficiency particulate air filtration systems might have been a better alternative (9) but were not available at that time. No staff member involved consequently developed COVID-19.

\section{Methods}

Use of a rigid tracheostomy tube for initial tracheotomy is a matter of debate. The key principles include avoidance of unnecessary interventions (9). Therefore, we decided to use a rigid cannula to facilitate clearance of secretions and speaking later on, without the need to change the whole cannula. Endoluminal repair is the least traumatic way of
TML reconstruction $(5,11,12)$. Conservative methods do not connect the edges of the posterior tracheal membrane and therefore leave a weak area with potential hernia formation of mediastinal tissue. Furthermore, in this patient, stabilization of the posterior wall was essential as otherwise recurrent tube dislocations and further widening of the lesion and progression of mediastinal emphysema were otherwise likely to have occurred. The idea of open repair through posterolateral thoracotomy was rejected as the patient was frail and COVID-19 is associated with highly increased operative mortality (Appendix 1).

\section{Outcome}

The patient's recovery was slow, which is not uncommon for severe COVID-19 infection with long term mechanical ventilation, including comorbidities, critical illness and complicating CMV pneumonitis. Finally, she could be completely weaned off mechanical ventilation and supplementary oxygen and could be transferred to a rehabilitation clinic. Her hoarseness, which was reported at discharge, might be a complication of the endoluminal repair but also of a viral neuritis, critical illness neuropathy, and laryngeal edema respective dysfunction due to long term intubation. Finally, her main complaints were a general weakness and dyspnoe on minor efforts. As this is the first report of endotracheal TML repair in a COVID-19 patient, the procedure could not be compared with other reported cases.

\section{Conclusions}

This case demonstrates that iatrogenic TML may be managed with endoluminal repair, even in difficult circumstances such as ongoing COVID-19 infection. Nevertheless, such routine procedures usually performed without infectious risk, still illicit uncertainty concerning safe performance in COVID-19 patients because of possible aerosol release.

\section{Acknowledgments}

We thank Laura Reynolds for her help in language editing. Funding: None.

\section{Footnote}

Reporting Checklist: The authors have completed the CARE 
reporting checklist. Available at https://ccts.amegroups. com/article/view/10.21037/ccts-21-27/rc

Peer Review File: Available at https://ccts.amegroups.com/ article/view/10.21037/ccts-21-27/prf

Conflicts of Interest: All authors have completed the ICMJE uniform disclosure form (available at https://ccts. amegroups.com/article/view/10.21037/ccts-21-27/coif). SW serves as an unpaid editorial board member of Current Challenges in Thoracic Surgery from December 2019 to November 2021. The other authors have no other conflicts of interest to declare.

Ethical Statement: The authors are accountable for all aspects of the work in ensuring that questions related to the accuracy or integrity of any part of the work are appropriately investigated and resolved. All procedures performed in this study were in accordance with the ethical standards of the institutional and/or national research committee(s) and with the Helsinki Declaration (as revised in 2013). Written informed consent was obtained from the patient for publication of this case report and accompanying images. A copy of the written consent is available for review by the editorial office of this journal.

Open Access Statement: This is an Open Access article distributed in accordance with the Creative Commons Attribution-NonCommercial-NoDerivs 4.0 International License (CC BY-NC-ND 4.0), which permits the noncommercial replication and distribution of the article with the strict proviso that no changes or edits are made and the original work is properly cited (including links to both the formal publication through the relevant DOI and the license). See: https://creativecommons.org/licenses/by-nc-nd/4.0/.

\section{References}

1. Pfeifer M, Ewig S, Voshaar T, et al. Position Paper for the State of the Art Application of Respiratory Support in Patients with COVID-19 - German Respiratory Society.

doi: $10.21037 /$ ccts-21-27

Cite this article as: Öztürk $\mathrm{K}$, Westhoff $\mathrm{M}$, Welter S. Endotracheal repair of an iatrogenic tracheal laceration in a COVID-19 patient scheduled for surgical tracheostomy: a case report. Curr Chall Thorac Surg 2023;5:12.
Pneumologie 2020;74:337-57.

2. Fowler RA, Guest CB, Lapinsky SE, et al. Transmission of severe acute respiratory syndrome during intubation and mechanical ventilation. Am J Respir Crit Care Med 2004;169:1198-202.

3. Schünemann HJ, Khabsa J, Solo K, et al. Ventilation Techniques and Risk for Transmission of Coronavirus Disease, Including COVID-19: A Living Systematic Review of Multiple Streams of Evidence. Ann Intern Med 2020;173:204-16.

4. Okada S, Ishimori S, Yamagata S, et al. Videobronchoscope-assisted repair of the membranous tracheal laceration during insertion of a tracheostomy tube after tracheostomy. J Thorac Cardiovasc Surg 2002;124:837-8.

5. Welter S, Jacobs J, Krbek T, et al. A new endoscopic technique for intraluminal repair of posterior tracheal laceration. Ann Thorac Surg 2010;90:686-8.

6. Schneider T, Volz K, Dienemann H, et al. Incidence and treatment modalities of tracheobronchial injuries in Germany. Interact Cardiovasc Thorac Surg 2009;8:571-6.

7. Pappachan B. Acute airway distress secondary to iatrogenic injury during Tracheostomy. J Maxillofac Oral Surg 2009;8:91-3.

8. Grewal HS, Dangayach NS, Ahmad U, et al. Treatment of Tracheobronchial Injuries: A Contemporary Review. Chest 2019;155:595-604.

9. McGrath BA, Brenner MJ, Warrillow SJ, et al. Tracheostomy in the COVID-19 era: global and multidisciplinary guidance. Lancet Respir Med 2020;8:717-25.

10. Chiesa-Estomba CM, Lechien JR, Calvo-Henríquez $\mathrm{C}$, et al. Systematic review of international guidelines for tracheostomy in COVID-19 patients. Oral Oncol 2020;108:104844.

11. Welter S, Krbek T, Halder R, et al. A new technique for complete intraluminal repair of iatrogenic posterior tracheal lacerations. Interact Cardiovasc Thorac Surg 2011;12:6-9.

12. Welter S, Essaleh W. Management of tracheobronchial injuries. J Thorac Dis 2020;12:6143-51. 


\section{Supplementary}

\section{Discussion}

I congratulate the authors for successfully performing endoluminal repair of a $5 \mathrm{~cm}$ membranous wall tear of the trachea due to tracheostomy procedure. It is certainly not an easy task!

\section{Dr. Hon Chi Suen (Hong Kong, China): Was there much tension when you pulled the two edges together?}

Answer: Thank you very much Dr. Suen for your valuable comments and important questions.

Indeed, there is some tension on the suture especially the edges are retracted and the tissue is already shrinking. Because we apply a running suture, I think the tension is equally distributed to 7 or 8 stiches.

\section{Dr. Suen: Could you show pictures of the final product immediately after repair and some time later?}

Answer: The end result was controlled at POD 1 and is depicted in Figure 2E. Unfortunately, I have no better photographs as all other flexible bronchoscopies were performed on the ICU without taking photos. Taking all written assessments into account, no dehiscence was noted at follow-up.

\section{Dr. Suen: Would you consider putting the patient on ECMO during the period for the repair only because that can avoid jet ventilation and the risk of spreading the virus?}

Answer: Putting the patient on ECMO would be a possible way to avoid virus spread. But I would not because endoluminal repair is indicated to offer the least invasiveness and avoid additional operative access. ECMO is always associated with a certain bleeding tendency which would impair clarity of the operative field and would distribute more blood into distal airways. Furthermore COVID-19 patients on ECMO, as far as I know, do survive in less than $50 \%$. It is unclear, if weaning from ECMO in this patient would be possible immediately after the procedure.

Dr. Suen: Finally and maybe the most important question is: what advice would you give to prevent tracheal membranous wall tear during tracheostomy or intubation?

Answer: This question is most important. At first, I want to point out, that tracheostomy in COVID-19 patients are demanding procedures that should be performed from experienced specialists only. Secondly the selection of the cannula should be individualized to anatomical circumstances and its introduction into the tracheal lumen should be under direct vision and not be covered from fat or blood clots. No extra force should be used to move the cannula forward in case of local resistance. This are all simple basics, but they are important to mention when the patients $\mathrm{SaO} 2$ goes down quickly in apnoe and the surgeon is pressed for time. 